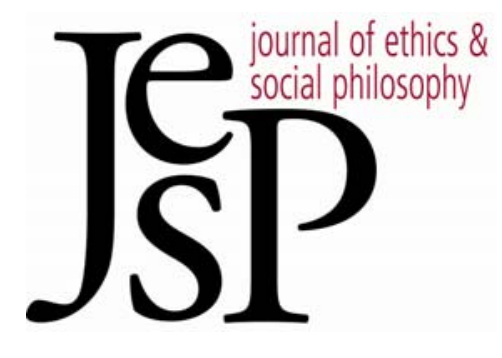

\title{
DEVIANT Formal CAUSATION
}

\author{
BY SARAH K. PAUL
}

Journal of Ethics \& Social Philosophy

Vol. 5, No. 3| APRIL 2011

URL: WWW.JESP.ORG

COPYRIGHT (C) SARAH K. PAUL 2011 


\title{
Deviant Formal Causation*
}

\author{
Sarah K. Paul
}

N ARM GOES UP; IT IS A SIGNAL that the assassination is to go
forward. The physical process that transpired could equally have
been a stretching, a voting, or a taxi-hailing, but this particular process was in fact a signaling. The context in which the arm-rising took place was surely relevant to determining which action it was, for no amount of flailing can constitute a taxi-hailing on a deserted island, or a voting in a monarchy. But let us somewhat improbably suppose that our arm is in a context where its rising could have constituted any of these things. The question is why it was in fact a signaling. And as the physical properties of the arm and its setting do not tell us, the natural place to seek an answer is in the armwielding agent's thought. In some way, the agent's own understanding of the event of the arm-rising contributes to determining the further descriptions under which that event constitutes the intentional action that it is.

How is this relation between thought and action to be understood? The broader aim of this paper is to highlight a particular constraint that any theory of action proposing to answer that question must satisfy. There is an architecture present in intentional action that must somehow be reflected in the agent's practical thought, and I will argue that the task of accounting for this structure strongly favors some ways of thinking about moral psychology over others. The motivation for this claim involves a second aspiration that I believe has independent interest for our understanding of mental causation: to identify a phenomenon I will take some poetic license in labeling deviant formal causation. ${ }^{1}$ The phenomenon concerns a type of mismatch between practical thought and the resultant action, and merits the label in its resemblance to the problem of deviant causation that plagues the so-called Causal Theory of Action. I will argue that whereas the Causal Theory is thought to be vulnerable in its susceptibility to the problem of deviant causal chains, the "noncausal" neo-Anscombean theory of action that is an increasingly popular alternative faces its own form of deviance $-\mathrm{a}$ form of deviance that the Causal Theory is well equipped to handle. The point will be that in accounting for the relation between thought and action, there is more than one kind of way in which the two may deviate. And insofar as the Causal Theory of Action is less vulnerable than the alternatives to the kind of deviant formal causation I

*This paper owes much to conversations with and papers given by David Horst, Matthias Haase, Agnes Callard, Sebastian Rödl, Michael Thompson and other participants in the 2010 Practical Knowledge II Workshop in Basel. Thanks also to Larry Shapiro, Mike Titelbaum, Alan Sidelle and Dennis Stampe for their thoughtful comments, and to Ben Wolfson and Michael Bratman for very helpful comments on an earlier draft. A much earlier version of this paper was presented at the 2010 Pacific APA, where I benefited from Daniel Guevara's comments and audience discussion.

${ }^{1}$ I owe this nifty label to Agnes Callard, although I am solely responsible insofar as its use here involves the taking of liberties. 
will illustrate, this point will amount to a new argument in favor of the Causal Theory.

\section{Actions, Causes, Deviance}

The Causal Theory of Action (CTA) traces back at least as far as Aristotle, ${ }^{2}$ but owes its contemporary heritage to Donald Davidson. ${ }^{3}$ It is not the most useful of labels, since there are theories of action opposed to the Davidsonian strand that nonetheless involve appeal to some form of causation. The causal commitment meant to be specific to Causal Theories concerns the pedigree of intentional actions: what distinguishes events that are intentional actions from other kinds of events is the causal antecedent of the event. Intentional actions are those behaviors that are caused to occur by some relevant psychological property of the agent, where the notion of "cause" in use here is efficient causation - "the primary source of the change or rest" of the agent. ${ }^{4}$ Particular theories may diverge with respect to precisely what this property is, but we may simply call it "intention." Actions are those things the agent intended to do (or appropriately related in some way to his intention), where intentions are some causally real state of the agent that explains the occurrence of the action.

The CTA holds that being caused by an intention is necessary to transform mere behavior into intentional action, but this condition is not meant to be sufficient. Not just any result with the right cause will count as having been done intentionally; the outcome must also accord in some sense with what the agent had in mind. The usual way to understand this claim is to take intentions to be not only causes but attitudes with representational content, where this content specifies the conditions that must be met if the outcome is to count as the intended action. Typically, this content will involve the representation of a goal or state of affairs toward which the action is directed, and perhaps a plan for how that goal is to be realized. Davidson notoriously held that the object of intention is given by the pairing of a belief and a proattitude that together constitute a reason for so acting,, but causal theories as such are not committed to this understanding of reasons as causes. One might rather think of intentions as sui generis states that do not intrinsically stand in a rationalizing relation to the action, but where the content normally does specify the agent's reason for so acting. ${ }^{6}$ But the general constraint is that there is some representation of the action with which the outcome must be in accord if it is to count as having been done intentionally. Thus, despite

2 Nichomachean Ethics, Book III, ch. 1: “...voluntary actions would seem to be those the moving principle of which is in the agent himself, he being aware of the particular circumstances of the action." (W.D. Ross, trans.)

3 As developed in the series of essays collected in Davidson (2001).

4 Aristotle, Metaphysics, v. 2.

${ }^{5}$ Davidson (1963).

${ }^{6}$ Setiya (2007). 
the label, the Causal Theory of Action imposes at least two conditions on an event's counting as an intentional action: it must be caused by a relevant intention, and it must accord sufficiently with the agent's representation of his aim.

These elements of the causal explanation are modally separable. Intention contributes to the causal explanation of action in virtue of the kind of attitude it is, for a range of represented actions; it is part of its functional role that for any $\phi$ (where $\phi$ stands for an action), being in this state with respect to $\phi$ will tend to cause the initiation of a $\phi$-ing and to guide one's behavior with respect to $\phi$-ing until the action is completed. Conversely, one can represent the very same $\phi$-ing without being in a state that will cause one to $\phi$, as when one deliberates about what to do prior to deciding on a course of action. One can imagine the action of building a squirrel house, hope to, or wish to without ever arriving at the state of intending that causes one to actually build it. Of course, the representation of squirrel-house building is not irrelevant to the behavior caused by the state of intending; it is not merely the initiation of the building that is causally explained by the intention, but the sustained progression from initiation to completion of the squirrel house. The causation and guidance of behavior must be somehow sensitive to the representative content of the intention. But the representation of the squirrel-house-building is independent of the causal powers of intending in the sense that the very same representation could feature as the content of a variety of other intentional states - beliefs, desires, wishes - and in that its satisfaction conditions could be met without the requisite behavior being caused by an intention.

Because of the modal separability of intention and representation, the CTA has always been subject to a serious objection influentially highlighted by Harry Frankfurt: the problem of deviant causal chains.? It is possible to devise scenarios in which (1) the agent intends to $\phi$; (2) what happens is in conformity with the agent's representation of what is to happen; and (3) that event was caused by the intention to $\phi$, but where what happens is accidental rather than intentional. Take the following example from Alfred Mele:

A philosopher intends to knock over his glass of water in order to distract his commentator. However, his intention so upsets him that his hand shakes uncontrollably, striking the glass and knocking it to the floor. ${ }^{8}$

\footnotetext{
${ }^{7}$ Frankfurt (1978). Frankfurt's example is of a man at a party who intends to spill his martini as a signal to his confederates in crime, but where this intention induces anxiety, which causes his hand to tremble and spill his drink (Mele (2001), p. 43). Davidson acknowledges the problem in "Freedom to Act," with his example of the climber who wants to rid himself of the weight and danger of holding another man on a rope, and believes that loosening his hold on the rope will accomplish this, but where this belief-desire pair causes the loosening waywardly by unnerving the climber (Davidson (2001), p. 79).

${ }^{8}$ Mele (1992), p. 182.
} 
The philosopher's intention is causally responsible for the result, and the result coincides with the satisfaction conditions specified by that intention, yet the result is not a case of intentional distracting. A general recipe for devising a deviant causal chain is to describe circumstances in which an intention causes an involuntary bodily response, and then to make it the case that this involuntary response satisfies the content of the intention purely by accident. Many attempts have been made to further refine either the causal condition or the representational condition, or both, in order to specify the right kind of causal connection and the right kind of representational accord in a way that will rule out cases of deviant causation. ${ }^{9}$ I will not run through these strategies here. I will merely state that although I find some of them promising, I take it there is no account that is generally accepted as solving the problem.

The problem of causal deviance is thought to be a reason to reject the Causal Theory in favor of views that are not vulnerable to this problem. ${ }^{10}$ One such competing approach is a strain of views we might call "neoAnscombean," in that this type of view is inspired by G.E.M. Anscombe's work on agency. ${ }^{11}$ It is claimed that the neo-Anscombean view can solve the problem of deviant causation and that this is a reason to prefer this type of view to the CTA. The central move, I will argue, can be understood as an appeal to a different kind of causation to explain what makes something an intentional action. Whereas the "Causal" theory designates a certain psychological feature as the efficient cause of intentional actions, the Anscombean view holds that the relevant factor is the formal cause of the action. The idea is that by shifting from efficient causation to formal causation, we avoid the problem of deviant efficient causation making accidental events seem to fit the bill of intentional actions when they should not.

\section{A Different Kind of Cause}

The obvious way to rule out the possibility of deviant causal chains is to bind together the elements that would otherwise be prone to deviate. The neoAnscombean's diagnosis of the CTA's problem targets the fact that the causal explanation of the action is held to be independent of the representational content that specifies the aim; the content is not itself part of the causal story. Even if it is added that the agent's behavior is guided in accordance with that content, explaining his progression from the initiation to the completion of the action, the fact remains that the content is external to the efficient cause of that progression. The solution, it is proposed, is to make the content an inextricable part of the causal story.

\footnotetext{
${ }^{9}$ See e.g., Bishop (1989), Wilson (1989), Mele (1992) and Enc (2003).

${ }^{10}$ As David Horst (ms.) points out.

${ }_{11}$ Primarily as developed in Intention (1963).
} 
The claim is that we must add to our understanding of agency the notion of thought as the formal cause of action. The formal cause of a thing is the account of what-it-is-to-be that thing - that which explains the conceptual shape taken by a particular bit of matter, in virtue of which it is formally the thing it is. Applied to agency, the idea is that intentional actions have a distinctive form, conferred upon them in some way by the agent's practical thought. They are not events that could either be intentional actions or not, depending on their efficient cause; the unity of an intentional action cannot be imitated by an unintentional occurrence. Although Anscombe herself did not explicitly characterize her theory of action as appealing to formal causation, I think it is a useful way to understand how her view has since been understood and developed.

I will first outline what I take to be central to the Anscombean approach to action theory, and then explain why some versions of that approach involve something like the idea of formal causation. Anscombe's remarks on action are notoriously opaque, and there are various ways of fleshing out her insights that merit the label "neo-Anscombean." I will use the label to circumscribe a set of views that take the key to action explanation to lie in the agent's "practical knowledge" of what he is doing. ${ }^{12}$ The unifying commitment of these views is that it is constitutive of intentional action that the agent have a special kind of "knowledge without observation" of what he is doing. Anscombe notoriously claimed that if an action is intentional, the agent will know without observing himself in action that he is performing that action, and that the declaration "I was not aware I was doing that" reveals that the action was not intentional. ${ }^{13}$ The genus of neo-Anscombean view I have in mind accepts this knowledge condition on intentional action, at least in some form, and ventures to explain it by appeal to a particular understanding of the will that I call "Cognitivism." ${ }_{14}$ Cognitivism takes the will to be in part a capacity for non-observational knowledge of action, and the

12 I am here thinking of work by Michael Thompson, Sebastian Rödl, Candace Vogler, Richard Moran, Martin Stone, Matthew Boyle, Douglas Lavin, Kieran Setiya and J. David Velleman. Although their views are each highly original and differ in many respects, I think they can be loosely grouped as having been influenced by the features of Anscombe's work discussed here, and as understanding the connection between intention, act-explanation and practical knowledge in a way that leaves them open to the challenge I will develop. I will not argue specifically that any of these particular views cannot meet that challenge, however.

13 Anscombe (1963), p. 14: "Now the class of things known without observation is of general interest to our enquiry because the class of intentional actions is a sub-class of it. I have already said that 'I was not aware I was doing that' is a rejection of the question 'Why?' whose sense we are trying to get at; here I can further say 'I knew I was doing that, but only because I observed it' would also be a rejection of it."

14 Paul (2009a, 2009b). Most neo-Anscombeans do not want to defend the epistemologically dubious thesis that the cognitive relation in question is always one of knowledge, and retreat to talk of belief. In this discussion, I will idealize away from epistemic accuracy in tending to speak of knowledge, bracketing admittedly important questions about the relevant justifiers and defeaters. But see Paul (2009a, 2009b) for a more precise and thorough discussion of the epistemology of practical knowledge. 
expression of the will - intention - to be a cognitive, belief-like state that embodies this knowledge. The strategy is to explain the datum that intentional action generally exhibits first-personal, non-observational knowledge of what one is doing by identifying this knowledge with the agent's intention in acting. An event is an intentional action just in case the agent is acting with an intention, where intention is understood as a kind of knowledge of what one is doing (at least, if all goes well). Most importantly, the claim is that the expression of the will embodies knowledge of the action one is engaged in because that knowledge is the cause of that action: the knowledge "is the cause of what it understands." 15

Here there is a divergence among Anscombeans in how to understand the appeal to "cause" in the Thomistic slogan, "cause of what it understands." J. David Velleman and Kieran Setiya have each proffered theories of intention and action that are Anscombean in taking knowledge of action to be the key to understanding agency and Cognitivist in taking intentions to be a kind of belief-like state that embodies the knowledge in question. ${ }^{16} \mathrm{Howev}-$ er, Velleman's and Setiya's views are versions of the Causal Theory; they take the causal power of the knowledge to lie in the efficient-causal relation between intention and action. I mention these views to set them aside for the present, though I will return to them in section 4. My interest here is in a type of view that takes the CTA to be mistaken in locating the cause of intentional action in its pedigree, such that the very same event could be an intentional action or not. Rather, this type of view takes intentional action to have a distinctive form that is not shared by unintentional events, where this form is inherited from the content of the agent's practical knowledge.

These ideas require elaboration. Let us begin with the form that is thought to distinguish intentional actions from an unintentional series of movements. Anscombe argues that being intentional is not some extra property of a material event that is independently specifiable; rather, an intentional action is an essentially distinctive kind of movement. ${ }^{17}$ To say that an event or process is intentional is to advert to a form of description of that event or process. A description is formally the characterization of an intentional action, on Anscombe's view, if it entails that the agent is thinking of the movement in a certain intrinsically practical way. The relevant form of thought has a practical character in at least two senses. First, in that the object of first-personal practical thought on this view is not simply a neutral representation that could also be the content of theoretical cognition: it is an action, or as Sebastian Rödl poetically puts it, "a thought that is a movement." 18 This is in part due to the second distinctively practical aspect of this kind of thought, namely, that it represents itself as the cause of the relevant

15 Anscombe (1963), $\$ 48$.

16 Velleman $(1989,2000,2007)$ and Setiya (2007).

17 Anscombe (1963), \$21. I've benefited in my characterization here from David Horst, Matthias Haase and Agnes Callard.

${ }^{18}$ Rödl (2007), p. 25. 
action's coming into existence. Without the presence of this practical cognition, the movement will fail to come under the description of intentional action. ${ }^{19}$

Part of what distinguishes practical thought on this view is that it has a teleological structure: it is intrinsically goal-directed. Actions are goal-directed processes that inherit their structure from practical thought. A typical episode of practical reasoning will issue in a conclusion of the form "I will do Z by doing A, B and C," thereby unifying ABC into the teleologically structured action of $\mathrm{Z}$-ing. Actions are in turn explained by way of revealing this structure by specifying the goal toward which a particular act-process is oriented. Anscombe suggests that this structure can be exposed by the agent's reply to the question "Why are you doing A?", where the question, if given application at all, will be answered by providing a further consideration in light of which A-ing can be grasped as instrumental or fitting. The answer to the "Why?" question thus functions to reveal the thought that unifies a series of events into an intentional action, disclosing the broader goal of which the current episode is an instrumental part as the agent conceives of it. More precisely, what happens will amount to an intentional action under all and only those further descriptions the agent is in a position to offer in answer to the "Why?" question without appeal to observation of what he is doing. The same action may be intentional under a series of descriptions, but they must be the very descriptions under which the agent conceives of the action; his rejection of a description as something he did not know he was doing, or knew of only by discovering that it was so through perceptual means, reveals the action to be unintentional under that description. ${ }^{20}$

But in addition to constituting an explanation of action, Anscombe famously claims that the answer to the "Why?" question is also the expression of a special kind of "practical knowledge." ${ }_{21}$ The conclusion of practical reasoning is a representation of action that is belief-like in the sense that it is capable of embodying knowledge of actually performing that very action. The judgment "I am doing A because I am doing Z, and A is a way of Z-ing" is at once the expression of one's intention to be Z-ing by way of A-ing and knowledge that one is Z-ing and thereby A-ing, barring a complete misfire of execution. That is, provided there is not a serious rift between what happens and what one would say one is doing, practical thought embodies knowledge of what one is doing intentionally:

19 Anscombe (1963), \$42.

20 Of course, most any successful action will rely upon perceptual input, and to have knowledge of one's action under the perfective aspect "I have $\phi$-ed," perceptual confirmation of having succeeded in performing a $\phi$ action will normally be required. The claim is merely that the agent must have knowledge of the action as in progress, under the imperfective aspect "I am $\phi$-ing," which does not entail the truth of the perfective "I will have $\phi$-ed." ${ }^{21}$ Anscombe (1963), $\$ 32$ and 45. 
When knowledge or opinion are present concerning what is the case, and what can happen - say $Z$ - if one does certain things, say $A B C$, then it is possible to have the intention of doing $\mathrm{Z}$ in doing $\mathrm{ABC}$; and if the case is one of knowledge or if the opinion is correct, then doing or causing $\mathrm{Z}$ is an intentional action, and it is not by observation that one knows one is doing $\mathrm{Z} . .^{22}$

Schematically, the proposal for how to understand this enigmatic claim is as follows. In the absence of the intention to $Z$ by way of $A B C$, there will be no intentional action of Z-ing. But given that certain background conditions are met, ${ }^{23}$ the presence of the intention is generally sufficient to transform the ensuing material process into an intentional Z-ing. The intention brings ABC together under the teleologically ordered concept of Z-ing, and provided the world does not radically refuse to cooperate, it is thereby made true that one is intentionally doing Z. By constituting the fact of the matter, the thought "I am Z-ing by way of ABC" thus amounts to knowledge. It emerges that what the agent does intentionally is what he knows non-observationally that he is doing, where his thought amounts to knowledge in virtue of its role in imposing the form on the action. There is an internal relation between intending and doing; hence Anscombe's slogan that practical knowledge is "the cause of what it understands."

We are now in a position to see how this approach to understanding action may be understood as referencing a kind of formal causation. ${ }^{24}$ Practical knowledge confers the form of intentional action upon what happens, imposing a teleological unity on a series of events and thereby transforming them into a new kind of thing. What results - an action - is not a process that could have been caused in any other way. This is an important point on which the neo-Anscombean view conflicts with the Causal Theory, since the CTA's explanation of intentional action by appeal to the efficient cause of a process allows that the same material process-type could be brought about by other means (though lacking the status of intentional action). The formal cause transforms the material; the efficient cause need not. The shift from efficient cause to formal cause thus precludes the original problem of deviant causation. If the thought that specifies the satisfaction conditions of the intention is at the same time what brings those conditions into existence, there cannot be an event that mimics the form of an intentional action but that is caused in an accidental way. If the representation of action - the agent's practical knowledge of what he is doing - is intrinsically causal, its presence

22 Anscombe (1963), \$28.

${ }^{23}$ Namely, knowledge of one's circumstances and the causal relationship between A, B, C and $\mathrm{Z}$.

${ }^{24}$ Again, I do not mean to attribute the appeal to formal causation to Anscombe herself, as she never explicitly described her view in this way. Particular neo-Anscombeans might also balk at the label, for worry of importing other Aristotelian distractions. My interest in describing the view as appealing to formal causation is not in the fine Aristotelian details, however, but simply to highlight the contrast between the kind of action explanation offered by the neo-Anscombean in contrast to the CTA. 
entails that there will be something that comes under the form of description of intentional action, and its absence entails that there is nothing that conforms to the action he intended.

It is crucial to the avoidance of deviant causal chains that on this view, it is sufficient to explain the agent's psychological contribution to his action to cite his practical knowledge of the action. We need not advert to any additional motivational state such as "wanting" or "desiring" to account for what it was that moved the agent. What explains action is the agent's cognitive grasp of how his proximate and distal goals are teleologically related, not some propulsive psychological force. Indeed, Anscombe was skeptical that we can make sense of "wanting" independently of "trying to get" - that is, independently of taking as a goal. ${ }^{25}$ To be sure, as Michael Thompson has argued, act explanation may assume the superficial form "she A-ed because she wanted to B," but the Anscombean resists the assumption that this formulation refers to some further conative spring of action. ${ }^{26}$ Rather, the appeal to "wanting" here is simply a linguistic mechanism for specifying a more distant goal of the agent's: he is laying the groundwork for B-ing by A-ing, but has not yet begun the process of B-ing itself.

In sum, because the explanation of the form of an intentional action makes reference only to the agent's practical knowledge and has no further moving psychological parts, we avert the problem of deviant efficient causation. Mele's philosopher did not have practical knowledge of distracting the speaker by way of upsetting his glass; he did not represent the particular hand-movement he made as a phase in the process of a distracting, and it is therefore not explicable by appeal to that further goal. We do not have the form of action here, but only a disunified collection of events - a spasm, a glass falling over, a speaker forgetting her place.

\section{Deviant Formal Causation}

Viewed in this light, the move to understanding intentional action as having a distinctive internal form rather than as an event with a distinctive causal pedigree appears to be an elegant solution to the problem of deviance. My purpose in this section is to argue that in its Anscombean guise, at least, the solution is in fact unstable as it stands, and introduces significant problems of its own. It is essential to keep track of two separate commitments that are brought together in the theory under consideration: the Cognitivist claim that the psychological contribution to action explanation is a belief-like state that embodies knowledge of action (when all goes well), and the proposal that the explanatory role played by the content of that knowledge is as formal cause of what it represents. I will argue that these two commitments together result in a relation between practical thought and action that is too strong. Specifi-

25 Anscombe (1963), §36.

26 Thompson (2008). 
cally, by making practical knowledge the psychological determinant of what action is performed, the view problematically obscures the crucial distinction between intended aim and foreseen side effect. Non-observational knowledge of what one is doing is simply a broader category than intention, and is therefore capable of including too much in the constitution of action. This leaves the theory vulnerable to a different kind of deviant causal path by which an effect is counted by the theory as part of the intended action when it should not be: deviant formal causation.

I will illustrate the problem by considering a pair of examples culled from Anscombe herself. ${ }^{27}$ Imagine two gardeners, each of whom is moving his body in precisely the same way. Each grasps the handle of a water pump and moves his arm up and down, thereby operating the pump, thereby causing water to flow into the cistern that is the water supply for his employers' house. Further, each has been informed by a reliable source that there is poison in the water being pumped, and each knows that the inhabitants of the house will drink the poisoned water once it is in the cistern. The two gardeners thus have precisely the same knowledge of the causal chain that holds in these particular circumstances between the arm movement, the operation of the pump, the replenishing of the water supply and the inhabitants of the house being poisoned. And with respect to the external physical descriptions of what happens in each case, the scenarios are identical.

However, when we inquire of each gardener why he is acting so as to bring about the poisoning of the inhabitants (a gang of evil politicians), the two examples diverge. The first gardener replies, confidentially: "To polish that lot off; if we can get rid of them, the other lot will get in, see ...." Let us call him Murderous Gardener. The "Why?" question implies that Murderous Gardener is in fact carrying out a poisoning of the inhabitants, and his reply amounts to an acceptance of this implication, revealing that he knows without observation that he is poisoning them. Further, his answer implies that he takes himself to have sufficient reason to act so as to poison them. It suggests in particular that their death is a goal of his, grasped as instrumental to effecting a political regime change.

In the second case, the gardener replies to the "Why?" question by snapping: "I didn't care about that; I just wanted to earn my pay." We may call him Indifferent Gardener. Indifferent Gardener's answer implies that the death of the inhabitants is not in general one of his goals. His goal is to earn his pay, to do which he must discharge his duties, one of which is refilling the house cistern. Strikingly, though, his reply equally reveals that he has nonobservational knowledge of bringing the poisoning about. In virtue of his background knowledge that the only water available to refill the cistern has poison in it, he knows that his pursuit of the goal of earning his pay involves poisoning his employers. Thus, he acts in the knowledge that he is bringing

27 Anscombe (1963), \$23-36. 
about the poisoning, and like Murderous Gardener takes himself to have sufficient reason for so acting.

Intuitively, the Murderous Gardener and the Indifferent Gardener did not perform altogether the same action. Actions are internally goal-directed, and the gardeners' efforts were in some sense directed at different things: Murderous Gardener's efforts are directed at the poisoning, while Indifferent Gardener's efforts are not. The natural thing to say about the Indifferent Gardener's relation to the poisoning is that it is a foreseen side effect of aiming at wage-earning by way of replenishing the cistern with what happens to be poisoned water. The poisoning is not part of that aim, and may or may not be unfortunate from his point of view, but he is determined to proceed in the knowledge that he is bringing this effect about. The natural thing to say of the Murderous Gardener, in contrast, is that he intends the poisoning. It is important to emphasize that this classification is not meant to rest on differing moral evaluations of the two gardeners and their motives. The difference in the structure of the respective actions, loosely characterized by the notion of "aim," is meant to be at bottom a metaphysical one and need not depend on any prior moral evaluation of the gardeners' deeds.

The question is what, if anything, vindicates this intuitive metaphysical difference. The virtue of these twin scenarios is that they hold fixed many of the potential grounds for this distinction: the contexts in which the actions occur are identical, as are the gardeners' bodily movements and the physical descriptions of the ensuing chain of events. If they have performed different actions, it seems the explanation must reference their respective psychological relations to those events. The point of setting it up this way is to illustrate that if the physically identical poisoning-event has the status of intended action in one case and expected side effect in the other, this asymmetry can only be traced to divergent psychological properties of the two gardeners. The challenge, then, is whether and how this distinction can be vindicated by a neo-Anscombean theory of action.

Suppose with the Anscombean that what is done intentionally inherits its form from the agent's practical knowledge: the fact of the matter as to what action he performs is given by the content of his non-observational knowledge of what he is doing. The problem immediately arises that on the surface, each gardener appears to have precisely the same non-observational knowledge of what he is doing. Murderous and Indifferent Gardener each knows full well, and in a non-observational way, that in moving his arm up and down he is operating the water pump, thereby refilling the cistern, and thereby poisoning the inhabitants. Further, this knowledge has a practical orientation in the sense of determining the thing known, in that in the absence of this knowledge, there would be no intentional action that comes under all of those descriptions (though it would beg the question at this point to say that the action is intentional under all of these descriptions). Specifically, what is problematic is the particular bit of non-observational knowledge both gardeners appear equally in possession of and entitled to: "By refilling 
the cistern, I am hereby poisoning the inhabitants of the house." The very same series of events is occurring in each case, and both gardeners have nonobservational knowledge of these events that includes the description "poisoning." It looks for all that has been said as though Murderous Gardener and Indifferent Gardener have performed the same action after all.

What has happened to the Indifferent Gardener is the problem I would like to call "deviant formal causation," taking a bit of liberty with the requisite notions. The worry is that if we understand the thought that serves as the formal cause of intentional action solely as a kind of cognitive, belief-like grasp of what one is doing, even where this cognition has a world-to-mind direction of fit, we get actions with what is intuitively the wrong form where foreseen side effects are concerned. If it is necessary and sufficient for the formal causation of an intentional poisoning that the agent know he is bringing about a poisoning in virtue of the practical efficacy of that very bit of knowledge, the poisoning comes out as intended in the case of the Indifferent Gardener as well as the Murderous Gardener. The point of calling this result a matter of deviant formal causation is to illustrate that while the form of the Indifferent Gardener's movement is the form of a teleologicallyordered intentional poisoning (indeed, it is the action Murderous Gardener intends), and is in conformity with his non-observational knowledge of what he is doing, this conformity is accidental; it is ensured by Indifferent Gardener's background knowledge that in this particular case, doing his job involves replenishing the cistern with water that happens to be poisoned.

\section{Recovering the Form}

Let us consider possible ways for the Anscombean to meet this challenge. What is needed to avoid the problem of deviant formal causation is some further constraint on how the agent's knowledge of what he is doing confers the form of intentional action that will screen out the side effects. Anscombe takes the distinction between intended poisoning and side-effect poisoning to be marked by the disparate answers provided to the "Why?" question. Of course, the answer alone will not suffice. I take it that a difference at the level of dispositions toward verbal behavior will not in itself ground a metaphysical difference in what action is performed. It cannot be enough to change one's actions that one is disposed to say one thing rather than another about what one is doing. Where Murderous Gardener is disposed to supply a reason for poisoning in answer to the "Why?" question, Indifferent Gardener is disposed to disavow the poisoning and explain his behavior by reference to his desire to earn his pay. But of course, many people are disposed to disavow actions they fully intended to perform; something must make the relevant verbal declarations true.

Although the extent of the gardeners' non-observational knowledge of what they are doing is the same, perhaps what grounds the divergent answers is an underlying asymmetry in the structure of what they know. Presumably 
the Murderous Gardener is thinking of the poisoning as his aim, while the Indifferent Gardener thinks of it as a byproduct - are not these distinct modes of presentation enough to block the deviance problem? But it is essential to see that it is not an answer to the problem simply to help oneself to the notions of "aim," "means" or "end," and read the structure of what we intuitively take the agent to have done back into the agent's thought. We are after a theory that explains what it is to treat a state of affairs as an aim as opposed to a byproduct.

The natural thought at this point is to appeal to how the agents conceive of their reasons for action. The two gardeners do not differ in their knowledge of the event-process they are engaged in bringing about, but they do differ in the reasons they take to support these efforts. One way of giving content to this idea is to say that they differ in how they know nonobservationally what they are doing: they arrived at the content of that knowledge via different chains of reasoning. Both gardeners began deliberation with the knowledge that there is poison in the particular water at hand. Murderous Gardener proceeds to reason that in this situation, operating the pump handle is a way of replenishing the cistern, which is a way of poisoning the inhabitants, which is a way of achieving his goal of facilitating a regime change. He concludes that he has sufficient reason to operate the pump handle, thereby replenishing, thereby poisoning, and in so concluding comes to know that he is doing all of these things. Indifferent Gardener reasons that in this situation, operating the pump handle is a way of replenishing the cistern, which is a way of doing his job, which is a way of earning his pay. He takes this to be a sufficient basis for operating the pump handle and concludes that he is doing so. His knowledge of the water being poisoned does not feature in this reconstructed episode of practical reasoning; it must be deployed as a premise of further theoretical reasoning in order to reach the knowledge that in pumping, he is also bringing about a poisoning. The suggestion is that the divergent courses of the two gardeners' practical reasoning can ground the relevant distinction in the form of the two actions.

But the question remains as to what non-tendentious fact grounds the attribution of these particular chains of reasoning to the respective gardeners, even implicitly. It seems to me that the plausibility of these reconstructions tacitly appeals to an antecedent understanding of act-types - of general ways of doing things. Doing one's job is in general a way of earning one's pay, while poisoning one's employers is not generally a phase in the teleological event-type of pay earning. Hence we are inclined to suppose that a further, different kind of reasoning must be applied to reach the conclusion that this pay-earning is also a poisoning. But causation - even formal causation - is a relation between particulars; the object of practical knowledge is a particular action in a particular context. Both gardeners reason about what to do in this context, and with the knowledge that the water is poisoned. At the outset of deciding what to do, they have the same understanding of the efficient-causal relations in that context between pumping, replenishing and poisoning, and 
in conclusion, both decide that they have sufficient reason to proceed with their pump-operation. Viewed in this light, there is no non-question-begging reason to exclude the known connection between the pumping, the poisoned water and the inhabitants' drinking habits from the Indifferent Gardener's reasoning about what to do. His decision is made in light of his expectation that it will result in the poisoning, even if he grants that fact little or no weight, and the reconstruction of how he reached that decision ought to include that expectation. A vivid way of illustrating the point is to note that the Indifferent Gardener could truthfully have replied to the question "Why are you poisoning the inhabitants?" by providing a reason for action, namely "In order to earn my pay; I have to fill the cistern, and this is the only water there is. ${ }^{2} 8$

In essence, the proposed strategy presumes that a clean distinction can be made between the aspects of the reasoning leading up to the decision to proceed that are practical and those that are theoretical. ${ }^{29}$ The problem is that reasoning about what to do consists not only in determining what would be desirable and calculating necessary means, but also in calculating what the world would be like if one were to pursue one's desires. These latter calculations are theoretical, in a sense, but the deliverances thereof serve in turn as inputs to further practical reasoning concerning whether to act so as to bring about these consequences. That the inhabitants will get poisoned if the Indifferent Gardener proceeds is something he knows theoretically, but it is also a practical reason not to proceed. ${ }^{30}$ The point is that we cannot simply help ourselves to an antecedent understanding of which considerations informing the agent's knowledge of what he is doing are practical and which are theoretical. Each gardener has reflected on the same considerations and concluded that his reasons support initiating and seeing through the entire eventprocess he knows he is engaged in.

This insight suggests a revisionary strategy that the neo-Anscombean might pursue: simply to reject the category of expected side effect and hold that everything foreseen is intended. There is a rationale for including all expected consequences of a course of action in the content of the agent's intention. The Indifferent Gardener has foreseen that earning his pay by pumping the available water into the cistern will give rise to the inhabitants' being poisoned, and he has concluded that he has sufficient reason to proceed. There

${ }^{28}$ Pragmatically, refusing to provide a reason as an answer to the "Why poison the inhabitants?" question may be a way for the Indifferent Gardener to indicate that in another possible world where he could easily earn his pay without poisoning them, he would see his reasons for action differently. This is consistent with the claim that in the actual world, he took the fact that doing his job of refilling the cistern would earn him his pay to be sufficient reason to proceed with a course of action he knew to include poisoning them.

${ }^{29}$ Following the strategy proposed by Harman (1976) in his seminal exploration of the idea that intentions are a kind of belief.

30 Perhaps not directly, if Indifferent Gardener sincerely does not care one way or the other. But surely some desire Indifferent Gardener has to stay out of trouble would be thwarted by being an accessory to homicide. 
is thus an important sense in which the Indifferent Gardener has chosen the entire scenario he expects his operation of the pump to result in, and thereby accepted it. Sidgwick and Neri-Castañeda had this view of intention. As Sidgwick saw it, intention includes "not only such results of volition as the agent desired to realise, but also any that, without desiring, he foresaw as certain or probable." 31 And as Castañeda eloquently expresses the rationale for this view:

An action that one ponders and places as a side action in a plan leading to a goal action, is an action that one...accepts in spite of how painful it is, in order to attain that goal. This deliberate toleration is of the same family as the acceptance we call intending. It is harsh to cast a tolerated action aside and declare it nonintentional, just because it is not in the path of the goal..$^{32}$

There is hence independent reason to think of intention as including all that the agent has accepted he will do.

Anscombe herself called Sidgwick's view "obviously incorrect." ${ }_{33}$ I would not go this far; I do think there is an important kind of unity present in one's acceptance of all one foresees one will bring about in implementing a candidate action-plan. However, I also think the category of side effects is essential to preserve under some guise. There is an important difference between Indifferent Gardener and Murderous Gardener, even if they effect precisely the same differences in the world. In admittedly imprecise and mysterious ways, we rely on this distinction in our assignments of moral responsibility, praise and blame. I do not want specifically to defend Indifferent Gardener's conduct as morally permissible, but there are more compelling cases in which the distinction between what is intended and what is merely foreseen plays an important role in our understanding of what has been done and whether it was permissible. ${ }^{34}$ If the content of what is intended does not distinguish between side-effect and aim, some other way to ground our evaluative practices must be found.

The most promising possibility in this vein is to advert to elements of the agent's psychology other than his practical knowledge to distinguish aim from side effect. Perhaps the proper result might be achieved by appeal to the agent's desires, in the Humean sense of desire as passion or sentiment rather than goal. Possible Stocker cases aside, ${ }^{35}$ there will generally be some feature of the action-plan that appeals to one's desires; perhaps the content

31 Sidgwick (1907), bk. 1, ch. 5, §2.

32 Casteñeda (1979).

33 Anscombe (1958), 11.

34 As Philippa Foot, Judith Jarvis Thomson and Anscombe herself have influentially argued, among others. The morally interesting cases are ones in which the agent aims at some significant good, but foresees that pursuing that good in the planned way will have a harmful byproduct. The (not uncontroversial, but to me plausible) thought is that this is sometimes morally superior to bringing about that same harm as a means to one's ends.

35 Stocker (1979). 
of what is intended can be cleaved at what is intuitively the proper joint by reference to the agent's desiderative profile. Indifferent Gardener desires to earn his pay, and derivatively to replenish the water supply, because he takes refilling the cistern to be necessary for earning his pay. He does not desire the poisoning of the inhabitants as such, either directly or as a necessary condition on satisfying further desires he has. The proposal is that while the whole scenario is intended, the agent's desiderative profile serves to reveal the part of the content that counts as peripheral in the way needed for moral evaluations and the like.

But there is to my mind an insuperable problem with this way of imposing structure on the content of what is intended. On one hand, as Jonathan Bennett has emphasized, the state of affairs that would satisfy one's desires may be a surprisingly minimal aspect of what one intentionally brings about. ${ }^{36}$ In the classic example of the Terror Bomber who desires to induce terror in the enemy population by dropping bombs on the civilians, for instance, Bennett points out that strictly speaking, all the Terror Bomber requires to satisfy his desire is that the civilians appear to be dead for the duration of the war no need for them to actually be dead. For all his desires reveal, his means are limited to making it appear that the civilians are dead, while their actual deaths are merely the foreseen side effects of using bombs to make them appear dead. What this illustrates is that the desirability-characteristic the agent sees in a course of action may be a very thin slice of a complex situation even a nomologically impossible slice. Our Indifferent Gardener really only needs his employers to believe he is doing his job in order to be paid; one might then conclude that filling the cistern is a side effect of his inducing this belief by operating the pump handle in view of his employers, and that if he could do this without thereby filling the cistern, he would. The point is that the part of the content distinguished by reference to the agent's desires may often be far too narrow to ground the intuitive distinction between side effect and aim.

On the other hand, it is possible for the agent's desires to be overly expansive. "Indifferent" Gardener might in fact desire the deaths of the inhabitants, perhaps because he is a reluctant sadist. Still, it is intelligible that he might yet treat their poisoning as a side effect, and be committed to doing nothing extra to contribute to their perishing. That their deaths would bring him pleasure should not automatically ensure that it is a goal of his (though it might incline us to assign less credence to his avowal that it is not). The general problem may be described as this: we might have a kind-hearted Terror Bomber who desires the least amount of damage that is necessary for his goals, and a sadistic Strategic Bomber who is nonetheless resolved to target only the factory - and for all that, the one is still Terror Bomber and the other still Strategic Bomber. Cataloguing their desires will not reveal what they are treating as aims.

${ }^{36}$ Bennett (2001), 101-102. 
Note that this point is related to the aforementioned difficulty in nontendentiously distinguishing between practical and theoretical considerations in reasoning about what to do. Any strategy that rests on isolating our practical judgments about what is to be done from our theoretical judgments about what will then result will run up against the problem that one frequently cannot isolate just the effect one aims at from the rest of the causal order. The Terror Bomber aims at terrifying the enemy population by making the civilians appear dead; does this show that the content of his practical conclusion is limited to making the civilians appear dead, and that he then reasons theoretically that if he brings this appearance about via dropping bombs on them, they will actually end up dead? This does not seem to me a plausible account of the structure of practical deliberation.

In fact, there is a more general argument to be given as to why appeal to psychological features external to the agent's intention cannot assure the correct result. It is similar to the original charge made against the Causal Theory: that by positing multiple, logically independent determinants of intentional action, the possibility is necessarily left open that the external feature(s) will deviate from what is intended in a way that fails to support the structure we antecedently take to be there. I tentatively suggest that the reason is that the status of side effect is internally related to the concept of intention and cannot be underwritten by factors external to intention.

We are cast back to the original worry: by endowing a single representation as constituting both knowledge of and cause of what is being done, the problem of deviant efficient causation may be avoided, but at the cost of our ability to distinguish between goal and side effect. Knowing what one is doing, even where one is in position to supply a practical reason for so acting, is a broader category than intention.

\section{The Revenge of the CTA}

The payoff of this discussion is that in my view, a particular kind of Causal Theory of Action is well equipped to handle the problem of distinguishing between goal and side effect. It is crucial to note that merely adding intentions as efficient-causal mental states to the above conception of act-explanation will not solve the problem, since the trouble arises partly from the Cognitivism about intention. ${ }^{37}$ As long as the representational relation between agent and action is held to be a cognitive, knowledge-apt representation, the foreseen side effects will not escape inclusion in the content of what is intended. Beliefs by nature agglomerate; if the content of the intention is constituted by the agent's practical-reason-based beliefs about what he is doing and why, the agent will meet the conditions for intending everything he be-

37 Thus, although Setiya and Velleman have causal theories of action, their commitment to thinking of intention as a kind of belief that can embody practical knowledge leaves them as vulnerable to this problem as "non-causal" theories of action. 
lieves he is doing. That is, if we understand the conclusion of practical reasoning as a judgment having the form "I am doing A because I want to do B," this judgment should include all intersubstitutable descriptions of A known to the agent. This problem is not mitigated by adding that intentions are states that efficient-causally bring about their representational content.

The solution is to reject altogether the view of intention as the kind of cognitive, belief-like state that can embody knowledge. Rather, we should understand intention as a kind of non-cognitive practical commitment to action. ${ }^{38}$ The idea is that there is a part of the content of the agent's representation of what is to be done that he takes a distinctive non-cognitive attitude toward - a part he has undertaken a commitment to bringing about. It is no simple matter to articulate the nature of this commitment, and I cannot hope to do so here with any kind of thoroughness. What is of primary importance, though, is that it is an attitude that has a conative, world-to-mind direction of fit. It represents its content as to-be-done rather than being-done, thereby marking the boundary between aim and side effect, but can diverge from desire.

Forming an intention is the mental action involved in making an outcome one's goal. The proposal is to understand this as an act of commitment, where committing to a goal involves committing oneself to devising means to that goal, to committing to nothing incompatible with that end, to initiating a course of action geared toward that end when the time comes, and so forth. We can sometimes isolate these commitments by reflecting on the agent's behavioral dispositions in counterfactual situations that tease apart effects that are correlated in the actual world. In Indifferent Gardener's case, we must consider counterfactuals in which he learns that the outcome of the inhabitants getting poisoned is threatened - they are about to discover the truth, or they have switched to drinking bottled water - and ask whether he is disposed to make any extra effort to put the poisoning back on track. The lack of any such disposition indicates that he is not committed to that outcome. ${ }^{39}$ In contrast, he is committed to earning his pay, and derivatively to getting the cistern replenished, given that these are the means he has selected for earning his pay; he is disposed to reason further as to how to replenish the cistern, and to attempt alternative means if the pump does not suffice. Of course, all should agree that these counterfactuals hold, but my contention is that the agent's practical commitment is what supports and efficient-causally explains these counterfactuals. ${ }^{40}$

${ }^{38}$ In Paul (2009b), I used the phrase "practical commitment as a term of art, to refer to the whole-scenario conclusion of practical deliberation." Here and following, I do not mean to use the term in this technical sense. I mean "commitment" to take its ordinary colloquial sense, and "practical" to signify a non-cognitive, specifically agential kind of commitment.

39 As Bratman (1987) argues, ch. 10.

40 The theorist who thinks of the kind of causation involved in the relation between intention and action as formal causation might be inclined to counter that there is of course efficient causation in effect here as well, and that it is the latter that supports the side-effect- 
The individuation of precisely what the agent is practically committed to may be a complex and sometimes vague matter. As I am thinking of it, this commitment will inherit its structured content from the agent's upstream cognitions concerning his plan of action; it will depend on how the agent represents the action to himself, thinking of his ends and means as such, and how these distinctions are factored into the act of decision in which he makes the commitment. But it may be indeterminate even in the agent's own thought whether or not he is committed to a given foreseen effect. We would particularly expect this to be the case with respect to beneficial foreseen consequences, where the agent may not bother to decide whether he is committed to exerting any extra effort to bring them about if needed. And as in the case of most mental states, behavioral evidence might override the agent's own beliefs about what he is committed to. Ascertaining the boundaries of the agent's practical commitment may be epistemically impracticable, and it is possible for there to be no determinate fact of the matter.

Normally, however, there will be an at least rough fact as to which part of the scenario one has made a non-cognitive commitment to and which part one merely believes one will bring about in virtue of that commitment. Adding practical commitments to our moral psychology is needed to make sense of the way our goals can exceed our desires, but stop short of side effects where our beliefs do not. The question concerned what could underwrite the distinction between aim and side effect; the answer is that the attitude of intention functions to "point" to the aims and not the side effects, and to explain the agent's counterfactual dispositions to track only the aims. If the content of intention is regarded as to-be-done rather than as being-done, the efficient-causal efficacy of that attitude can serve as the truthmaker for the fact that the agent's efforts are directed at some aspects of his known circumstances and not others. In other words, commitment and belief can diverge at the joint of aim and side effect.

\section{Conclusion}

Let me conclude by reflecting on the limits of what I have shown here. I have argued that if we attempt to avoid the CTA's problem of deviant efficient causation by fusing causation and representation, we end up endowing that representation with a great deal of power. And specifically, if the representation in question is understood as a causally efficacious form of knowledge of what one is doing, the result is that foreseen side effects become included in the form of the resultant action. I take this result to suggest

revealing counterfactuals. Whatever it is that causes the agent's body to move in a way that amounts to a distinctive form of intentional movement, perhaps it is this causal property that explains the agent's dispositions to adjust his behavior to track some of the things he believes he is doing and not others. But this would reintroduce the deviant efficient causation problem with a vengeance, since one would have now divorced intention from the efficient causation not merely modally but in the normal case. 
two things: (1) that the psychology of agency cannot make do with purely cognitive, belief-like representations of the form "I am doing A because I want to do B," for this allows all known descriptions of what one is doing to be substituted for A; and (2) the understanding of intention as the efficient cause of action is well suited to ground the counterfactual dispositions to track those parts of the known causal order that are one's means and ends and not the side effects. The view that intentions are practical commitments that cause and explain the agent's intentional behavior can underwrite the distinction between aim and side effect in a metaphysically substantial way that does not simply make incorrigible the agent's occurrent thought or what he is disposed to say about his actions.

I do not take this discussion to have shown it to be impossible for the neo-Anscombean to meet the challenge of including only the means-end structure in the efficacious practical thought while rendering the expected side effects causally inert. It may be that a more sophisticated account of the structure of the representation of action than I have considered here can be given. At the least, then, the argument here can be taken as a way of highlighting substantive constraints on an adequate psychology of agency. Particular intentional actions have an internal means-end structure that must derive its identity from some feature of the agent's psychology, since with respect to what happened in the world, Indifferent Gardener and Murderous Gardener brought about precisely the same thing. The non-cognitive CTA explains this structure by reference to the causal efficacy of one's practical commitment, which supports the relevant counterfactuals. This approach is not open to the Anscombean, who must instead find a way of locating the structure in the content of the agent's cognition of his action, and explain what makes it true that the agent intends some parts of what he knows he is doing and not others. In the end, deviance plagues us all.

That said, I do not think we are left with a standoff. As I see it, the noncognitive Causal Theory is in a position to accept and absorb many of the insights of the Anscombean approach, whereas the converse is not the case. The Anscombean view is in a sense the more parsimonious of the two: it attempts to capture the structure of intentional action without positing a mental state of intention, and to explain the correlation between intentional action and non-observational knowledge by making the latter the cause of the former. This parsimony allows the view to remain appealingly silent on empirical questions regarding mental causation and to avoid the classic deviance problem of wayward causal chains. But in refusing to give a role to any kind of mental propulsion in action explanation, the Anscombean is left vulnerable to the objection that formal causation is "occult." Efficient causation must also enter into a complete account, since most intentional actions require that one's body move itself in a way that meets some minimum standard of progress toward the intended goal. This aspect of intentional action is not well explained by the notion of practical knowledge as formal cause. The efficacy of practical thought in producing the physical events involved in ac- 
tion remains to be accounted for in a way that does not simply collapse into the CTA, at the risk of advocating a kind of occasionalism.

The CTA is specifically crafted to explain the physical efficacy of practical thought, which I have argued gives it the resources to ground the counterfactuals needed to distinguish aim from side effect. But it can also learn from the Anscombean that the object of intention is not simply a state of affairs that can be replicated by a wayward causal chain: intentions are always to do something, where intentionally doing something has a form that is irreducible to a mere series of events. The CTA can incorporate this insight into its understanding of the representational content of intention and thereby into its causal explanation of action. Further, I have argued elsewhere that the non-cognitive version of the CTA I prefer can acknowledge Anscombe's insight that we generally have non-observational knowledge of what we do intentionally, and explain this knowledge inferentially, while denying that it plays a causal role in bringing the action about. In general, because the CTA is willing to countenance a richer moral psychology than the Anscombean, it can afford to take on many of the insights of the latter view. So while both views face challenges in capturing the relation between practical thought and intentional action, I do not think the problems of causal deviance constitute reason to abandon the Causal Theory of Action in favor of the Anscombean alternative.

Sarah K. Paul

University of Wisconsin-Madison

Department of Philosophy

skpaul@,wisc.edu 


\section{References}

Anscombe, G.E.M. (1963). Intention, Second Edition. Cambridge: Harvard University Press, 2000. (1958). "Modern Moral Philosophy.” Philosophy 33, no. 124.

Bennett, Jonathan (2001). "Foreseen Side Effects vs. Intended Consequences." In P.A. Woodward, ed. The Doctrine of Double Effect. University of Notre Dame Press.

Bishop, John (1989). Natural Agency: An Essay on the Causal Theory of Action. Cambridge University Press.

Boyle, Matthew and Lavin, Douglas (2010). "Goodness and Desire." Desire, Practical Reasoning, and the Good. Sergio Tenenbaum, ed. Oxford University Press.

Bratman, Michael (1987). Intention, Plans, and Practical Reason. Harvard University Press.

Casteñeda, Hector-Neri (1979). "Intensionality and Identity in Human Action and Philosophical Method." Nous, v. 13.

Davidson, Donald (1963). "Actions, Reasons, Causes." Reprinted in Davidson (2001).

\section{Press.}

Enc, Berent (2003). How We Act: Causes, Reasons, and Intentions. Oxford University Press.

Frankfurt, Harry (1978). "The Problem of Action." Reprinted in The Philosophy of Action. Alfred R. Mele, ed. Oxford University Press, 2003.

Harman, Gilbert (1976). "Practical Reasoning." Reprinted in The Philosophy of Action. Alfred R. Mele, ed. Oxford University Press, 2003.

Horst, David (ms.) "Practical Knowledge as an Account of Intentional Action."

Mele, Alfred (1992). Springs of Actions: Understanding Intentional Behavior. Oxford University Press.

Paul, Sarah (2009a). "Intention, Belief, and Wishful Thinking: Setiya on 'Practical Knowledge."' Ethics v. 119: 546-557. (2009b). "How We Know What We're Doing." Philosophers' Imprint, v. 9 , no. 11.

Rödl, Sebastian (2007). Self-Consciousness. Harvard University Press.

Setiya, Kieran (2007). Reasons Without Rationalism. Princeton University Press.

Sidgwick, Henry (1907). Methods of Ethics, Seventh Edition. Hackett Publishing Company.

Stocker, Michael (1979). "Desiring the Bad: An Essay in Moral Psychology." Journal of Philosophy 76, 12.

Thompson, Michael (2008). Life and Action. Harvard University Press.

Velleman, J. David (2007). "What Good Is a Will?" In Action in Context. Anton Leist \& Holger Baumann (eds.). de Gruyter/Mouton. (2000). The Possibility of Practical Reason. Clarendon Press. 
(1989). Practical Reflection. Princeton University Press.

Vogler, Candace (2002). Reasonably Vicious. Harvard University Press.

Wilson, George (1989). The Intentionality of Human Action. Stanford University Press. 